(Physiologisches Laboratorium in Bonn.)

\title{
Ueber die jungfräuliche Zeugung der Bienen.
}

\author{
Von
}

E. Pnüger.

Ferd. Dickel'1) suchte in diesem Archive Dzierzon's Lehre $\mathrm{zu}$ widerlegen, derzufolge unbefruchtete Eier der Bienen sich $z \mathfrak{u}$ entwickeln vermögen. Dickel's Ansicht hat lebhaften Wirlerspruch hervorgerufen und mir sogar den verblümten Vorwurf ${ }^{2}$ ) zugezogen, dass ich durch die Aufnahme von Dickel's Aufsatz in dieses Archiv gefehlt habe.

Die grosse, geradezu beleidigende Schärfe in der Polemik von Prof. Fleischmann gegen Dickel wurzelt in erster Linie in der Ueberzeugung $\mathrm{F}$ le is chm an n's, dass die Entwicklung unbefuchteter Eier bei den Bienen bewiesen sei. Ohne jeden Zweifel ist aber diese Parthenogenesis der Bienen eine mangelhaft begründete und sehr wahrscheinlich unrichtige Hypothese.

Wenn man an diese glaubt, muss man gleichzeitig eine Reihe von Thatsachen zugeben, die im höchsten Grade zweifelhaft erscheinen :

1. Aus den angeblich unbefruchteten Eiern des Bienenweibchens entwickeln sich nach heutiger Lehre nur Männchen.

2. Durch Befruchtung der Bieneneier mit männlichem Samen können niemals Männchen gezeugt werden. Die geschlechtliche Zeugung vermag bei den Bienen keine männliche Nachkommenschaft $z$ u erzielen.

3. Die männlichen Bienen (Drohnen) können niemals männliche, aber ausschliesslich weibliche Nachkommenschaft erzeugen. Die Drohnen sind also nur halbwerthige Männchen: ihr Hode hat nur die halbe Potenz.

1) F. Dicke1, Dieses Archiv Bd. 95 S. 66.1903.

2) Prof. Dr. A. Fleischmann in der Münchener Bienenzeitung Jahrg. 25, Nr. 17/18. 1. Sept. 1903. 
Liegt es nicht nahe, zu schliessen, dass die andere Hälfte der Potenz in dem Bienenweibchen steckt, welche den männerzeugenden Hoden besitzt, also Hermaphrodit ist?

Dass dieser Hode des Bienenweibchens bis jetzt unerkannt blieb, liegt wohl daran, dass seine Zellen keine Samenfäden erzeugen, die ja keine nothwendige Form des männlichen Zeugungsstoffes bilden. Dieser Dimorphismus desselben bei Drohnen und Bienenweibchen wird auch mit einer Verschiedenheit des Befruchtungsvorganges verknüpft sein; vielleicht ist der Spermakern in dem angeblich unbefruchteten Ei besonders klein, entbehrt der Strahlung, oder es vollzieht sich die Verschmelzung des Spermakerns mit dem Eikern so schnell, dass man nur selten den Vorgang zu Gesicht bekommt. Die betreffenden, bei Weismann ausgeführten mikroskopischen Untersuchungen scheinen ja auch vicht ganz negativ ausgefallen zu sein.

Ein Beweis für die Parthenogenesis würde gegeben sein, wenn es gelänge, ein als unbefruchtet vorausgesetztes, soeben von dem Bienenweibchen abgesetztes $\mathrm{Ei}$ durch künstliche Benetzung mit dem Samen der Drohne zum weiblichen Geschlecht zu zwingen. Dieser Versuch ist nicht gemacht und wird schwerlich gelingen. -

Aber ferner: Während bei den Bienen durch geschlechtliche Zeugung kein Männchen, soll bei den Psychiden (Scbmetterlingen) umgekehrt kein Weibchen gebildet werden können. Während bei den Bienen die "Parthenogenesis" nur die Entwicklung von Männchen, niemals von Weibchen ermöglieht, führt sie ungekehrt bei den Psychiden nur zur Bildung von Weibchen und niemals zu der von Männchen.

Diese widerspruchsvollen Räthsel verschwinden durch meine Erklärung. Das Vorkommen von Hermaphroditismus ist ja bei Bienen und Schmetterlingen beobachtet.

Die Parthenogenesis der Bienen, Schmetterlinge u. s. w. ist also ein bis jetzt dunkles Räthsel, dessen Lösung noch viele Arbeit nöthig machen wird. 







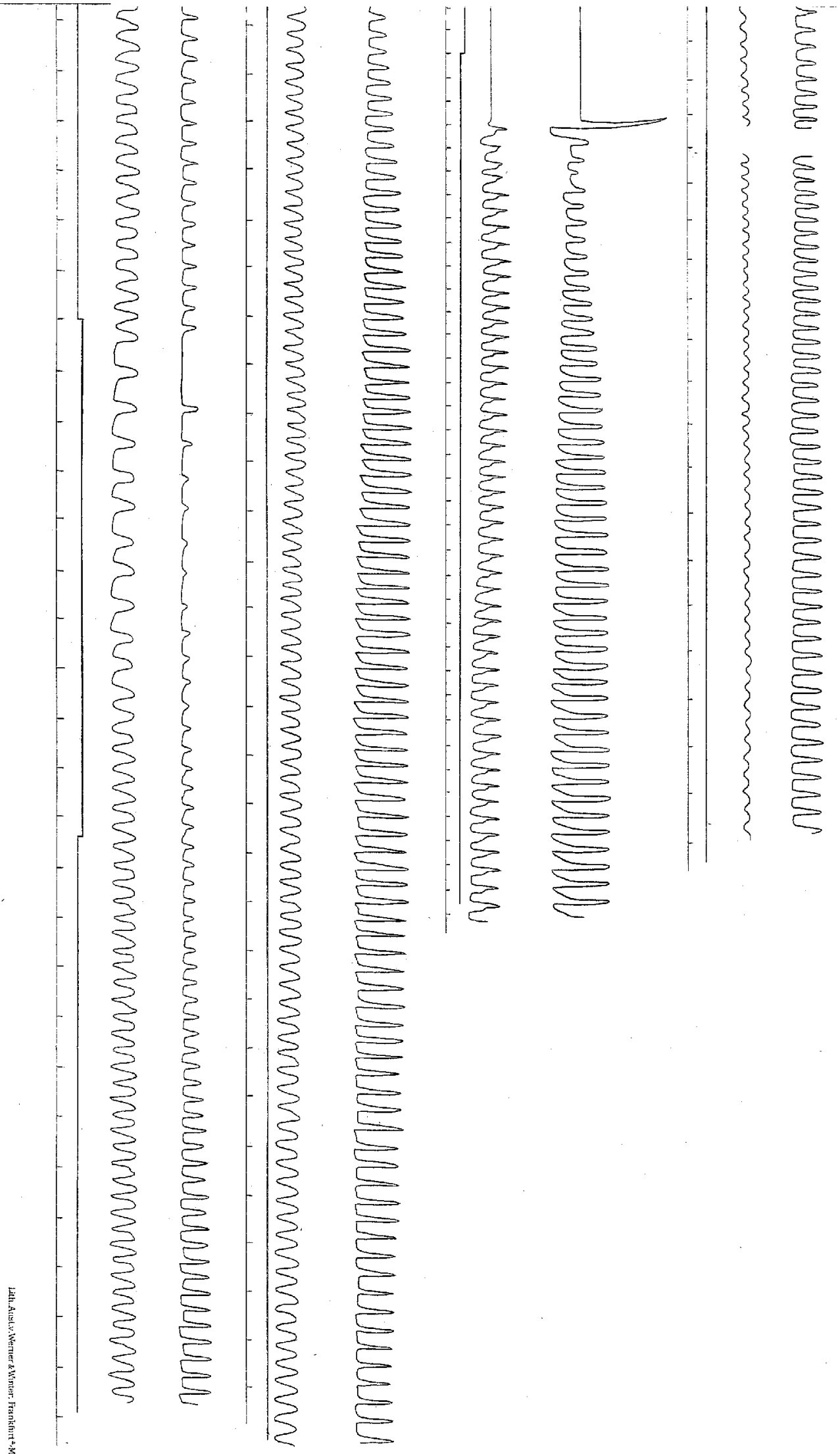

